DENZER, Jörg, Die Konquista der Augsburger WelserGesellschaft in Südamerika (1528-1556). Historische Rekonstruktion, Historiografie und lokale Erinnerungskultur in Kolumbien und Venezuela

\title{
Vincent Demont
}

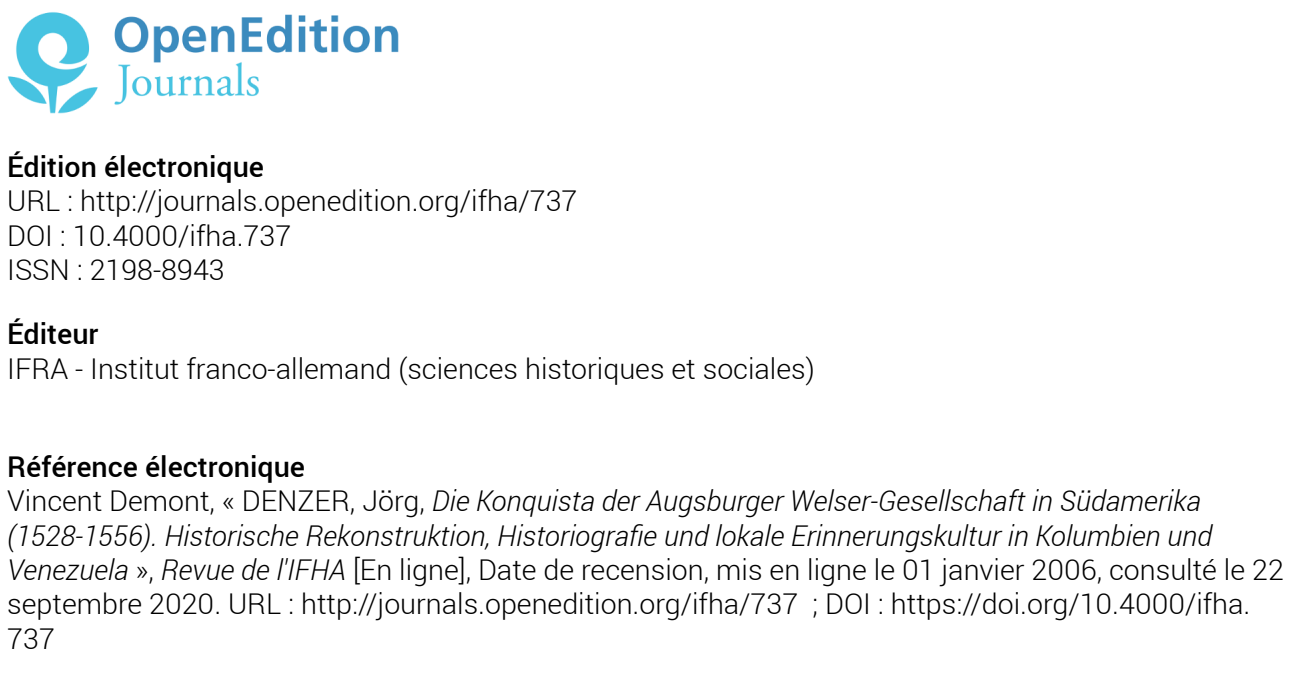

Ce document a été généré automatiquement le 22 septembre 2020.

(CIFHA 


\title{
DENZER, Jörg, Die Konquista der
} Augsburger Welser-Gesellschaft in Südamerika (1528-1556). Historische Rekonstruktion, Historiografie und lokale Erinnerungskultur in Kolumbien und Venezuela

\author{
Vincent Demont
}

1 Conquistar y poblar : conquérir et peupler. C'est la tâche qu'assigne à la maison des Welser l'asiento conclu en 1528 avec la monarchie hispanique, et qui lui accorde des droits sur le Nord-est de l'Amérique du Sud ; c'est pour elle que les marchands augsbourgeois financeront et organiseront six expéditions, et fonderont Coro, Maracaibo ou Bogota. Les Européens participant à l'aventure ne furent que quelques centaines : mais à ces groupes somme toute modestes, les chroniqueurs du XVIe s. comme les historiens contemporains accordent, rarement sans émotion ni sans arrièrepensée, une place de choix. C'est ce statut problématique, entre légende noire et mythe fondateur, forgé et modifié par cinq siècles d'historiographie, qu'explore le présent ouvrage.

2 J.D. donne d'abord, sur la foi de chroniques et de quelques rapports manuscrits, un récit détaillé de l'action menée par les Welser en Amérique latine. Au vrai, ceux-ci, déjà grands financiers de Charles Quint, contrôlent mal l'entreprise dans laquelle ils se lancent. Ce sont leurs facteurs, recrutés souvent pour l'occasion et, de par la durée des communications entre la Haute-Allemagne et Saint-Domingue (quatre à six mois pour un aller-retour), d'une grande indépendance, qui orienteront la colonisation espérée vers une économie de rapine, de brigandage et de pillage. En 1540, la découverte de l'empire Muisca, la fondation de Bogota et surtout l'établissement d'une liaison terrestre entre Pacifique et Atlantique, inciteront une monarchie hispanique désormais 
assurée de la continuité de ses possessions américaines à faire cesser l'anarchie de la conquête - et, en 1556, à évincer les Welser.

La nécessité de cette ample reconstruction historique (qui occupe une bonne moitié de l'ouvrage) n'apparaît que dans les deux dernières parties, elles plus strictement historiographiques. La mémoire écrite de l'action des Welser, du XVIe s. à nos jours, y apparaît fortement instrumentalisée : J.D. décrit comment la monarchie hispanique oriente et utilise récits de massacres et d'atrocités et plus encore leur attribution exclusive, contre toute vraisemblance, aux Allemands, puis analyse la reprise de cet héritage historiographique lors des indépendances sud-américaines. Si, en Colombie, ce sont des amateurs qui s'attellent à la tâche sinon avec méthode, du moins avec une certaine objectivité, l'histoire très vite professionnelle du Venezuela se voit strictement encadrée et, jusqu'à nos jours, utilisée. J.D. montre, par quelques aperçus de la mémoire orale de la conquête, les résistances bien sûr plus sociologiques que scientifiques aux thèses officielles, et tente d'en dresser une typologie.

4 De mouvement chronologique, et parfois construit comme une simple énumération, le livre aurait sans doute pu profiter d'un cadre argumentatif plus apparent. La clarté de l'écriture ne compense pas l'absence d'index ni surtout, pour qui ignore la localisation de la vallée des Pacabueyes ou de celle de Chinácota, de cartes. Novateur par son objet, et certainement très utile par ces thèses, l'ouvrage ne peut donc néanmoins prétendre constituer sur son sujet une œuvre de référence. 